\title{
Willingness to adopt wearable devices with behavioral and economic incentives by health insurance wellness programs: results of a US cross-sectional survey with multiple consumer health vignettes
}

\author{
Diego Soliño-Fernandez ${ }^{1}$, Alexander Ding², Esteban Bayro-Kaiser ${ }^{3^{*}}$ (1) and Eric L. Ding ${ }^{4,5,6,7^{*}}$ (1)
}

\begin{abstract}
Background: The number of health-related wearable devices is growing but it is not clear if Americans are willing to adopt health insurance wellness programs based on wearables and the incentives with which they would be more willing to adopt.

Methods: In this cross-sectional study we used a survey methodology, usage vignettes and a dichotomous scale to examine U.S. residents' willingness to adopt wearables (WTAW) in six use-cases where it was mandatory to use a wearable device and share the resulting data with a health insurance company. Each use-case was tested also for the influence of additional economic incentives on WTAW.

Results: A total of 997 Americans across 46 states participated in the study. Most of them were 25 to 34 years old (40.22\%), $57.27 \%$ were female, and $74.52 \%$ were white. On average, $69.5 \%$ of the respondents were willing to adopt health-insurance use-cases based on wearable devices, though $77.8 \%$ of them were concerned about issues related to economic benefits, data privacy and to a lesser extent, technological accuracy. WTAW was $11-18 \%$ higher among consumers in use-cases involving health promotion and disease prevention. Furthermore, additional economic incentives combined with wearables increased WTAW overall. Notably, financial incentives involving providing healthcare credits, insurance premium discount, and/or wellness product discounts had particularly greater effectiveness for increasing WTAW in the consumer use-cases involving participation: for health promotion $(R R=1.06$ for financial incentive, 95\% Cl: $1.01-1.11 ; P=0.018)$; for personalized products and services ( $R R=1.11$ for financial incentive, $95 \% \mathrm{Cl}: 1.01-1.21 ; \mathrm{P}=0.018)$; and for automated underwriting discount at annual renewal $(\mathrm{RR}=1.28$ for financial incentive, $95 \% \mathrm{Cl}: 1.20-1.37 ; P<0.001)$.
\end{abstract}

Conclusions: Under the adequate economic, data privacy and technical conditions, 2 out of 3 Americans would be willing to adopt health insurance wellness programs based on wearable devices, particularly if they have benefits related to health promotion and disease prevention, and particularly with financial incentives.

Keywords: Diffusion of innovation, Wearable electronic devices, Health insurance, United States

\footnotetext{
* Correspondence: esteban@uni-bremen.de; eding@post.harvard.edu

${ }^{3}$ Institute for Artificial Intelligence, University of Bremen, Bremen, Germany

${ }^{4}$ Department of Nutrition, Harvard Chan School of Public Health, Boston, MA

02115, USA

Full list of author information is available at the end of the article
}

(c) The Author(s). 2019 Open Access This article is distributed under the terms of the Creative Commons Attribution 4.0 International License (http://creativecommons.org/licenses/by/4.0/), which permits unrestricted use, distribution, and reproduction in any medium, provided you give appropriate credit to the original author(s) and the source, provide a link to the Creative Commons license, and indicate if changes were made. The Creative Commons Public Domain Dedication waiver (http://creativecommons.org/publicdomain/zero/1.0/) applies to the data made available in this article, unless otherwise stated. 


\section{Background}

It is forecasted that by 2020, the number of connected wearable devices worldwide will surpass 600 million devices [1]. Even though, wearable devices are well-known for their fitness and wellness applications, they have the potential to improve population health by moving the focus from disease treatment to prevention; routinely monitoring personalized physiological measurements; supporting self-management; identifying alterations in health conditions; and creating positive long term behavioral changes towards healthy lifestyles [2-4]. Despite these opportunities, it is not clear if innovations based on wearable devices will be successfully implemented in the heath sector because, among other reasons, external forces such as key industry players, funding, public policy, technology, customers, and accountability can foster or kill wearable-based innovations [3, 5].

Health insurance companies play a central role among those external forces, particularly in the U.S. healthcare system where more than half of the population is covered by private employer-based group insurance [6]. In the case of health insurance, insights from wearable devices could lead to a more customer-centric model that anticipates customers' risks and demands, and thus, enable new use cases related to continuous risk assessment; prediction of future health insurance claims; personalized insights to foster disease prevention; targeted marketing; customer engagement; and claims management [7-9].

In fact, wearables are gaining momentum in employerbased group insurance. For example, health insurance companies such as United Health Group, Humana, Cigna, and Highmark have established programs that foster the use of wearable devices at the workplace. In general terms, health insurance companies use wearable devices to promote wellness and prevention at the workplace and keep the progress accountable; and in exchange for healthy behaviors, employers receive economic incentives such as lower group premiums in their health insurance policy [10].

Previous studies have explained that health insurance companies could adjust their product strategies to motivate individuals to use wearable devices $[2-4,7-9,11-15]$ and even evaluated if consumers were interested to use a wearable device and share the data with their health or life insurance company in return for financial rewards for healthy behaviors $[16,17]$. However, little is known about the willingness to adopt health insurance wellness programs based on wearable devices, particularly those including use cases beyond health promotion. Therefore, the main goal of this study is to evaluate American's willingness to adopt wearables (WTAW) with behavioral and economic incentives by health insurance wellness programs. An additional goal is to explore the influence of economic incentives on WTAW.

\section{Methods}

\section{Population}

In this cross-sectional study, we used Amazon Mechanical Turk as platform to obtain our study population. Previous studies show that Amazon Mechanical Turk can be used to obtain high-quality data that is as representative of the U.S. population, in terms of gender, age, race, and education, as traditional subject pools $[18,19]$. Furthermore, it has been observed that participants from this online platform produce reliable results consistent with standard decision making biases [20].

Our target sample size was 1000 participants, so we posted two online surveys as a task in Amazon Mechanical Turk with a maximum limit of 500 respondents per survey. We randomized the opt-in process by posting both surveys the same day, and with the same title, description, and economic reward per response. Therefore, the two surveys had an almost identical positioning within Amazon's Mechanical Turk and participants had no means to differentiate one from the other before entering the survey. Regarding inclusion and exclusion criteria, we included participants that were U.S. residents and at least 18 years old, and we excluded respondents who tried to fill-in the same survey more than once.

\section{Use-cases}

We used a survey methodology based on vignettes to evaluate American's WTAW by health insurance wellness programs. Given our research methods and data collection process, institutional review board deemed this research exempt of ethics assessment.

Regarding the use-cases presented in the vignettes of the surveys, they were all based on insights from scientific articles [2, 4, 13, 14]; reports about health insurance technology [3, 7-9]; and recent news about trends in health insurance innovation $[10,21,22]$. The six usecases included were: health promotion, suggest actions to improve health status with a health assessment based on data from wearable devices; early detection of diseases, use data from wearable devices to identify certain diseases or disorders at an early stage; prediction of future health risks, use data from wearable devices to infer the likelihood of having a certain disease or disorder in the future; adherence tracking, wearable devices to identify specific movements such as smoking, drinking, eating or pill intake, and give actionable insights based on that data; personalized products and services, offer exclusive products and services related to wellness, health and insurance based on data from wearable devices; automated underwriting, speed up the process of applying or renewing the insurance policy by prefilling some fields with data from wearable devices. For additional information about the vignettes and the questions used in the surveys see Additional file 1 . 


\section{Willingness to adopt wearables}

Each survey had two main sections. The first section consisted of demographic questions to better understand the characteristics of the sample in terms of age group; gender; income level; ethnicity; state of residence; marital status; type of health insurance; and employment status. The second section contained a set of six hypothetical use-cases. Each use-case presented a scenario in which a fictional health insurance policy holder named "Peter" had to choose whether to "Accept" or "Do not accept" a new health insurance service where it was mandatory to use a wearable device and share its data with a health insurance company. In every scenario, respondents had to select what they would do if they were Peter. If they chose "Accept" we considered they had a high WTAW in that specific use-case, whereas if they chose "Do not accept" we considered they had no WTAW.

To evaluate the main barriers to accept health insurance use-cases based on wearable devices, in addition to the dichotomous choice of accept or not accept, there was an "Accept just if ..." option were respondents could select the conditions under which they would be willing to accept. These conditions included a free service; a free smart band; a service $100 \%$ accurate; data not shared with third-parties; and an "other" field where they could write their own requirements. If they chose "Accept just if ..." we considered they were willing to accept that specific use-case but only under certain conditions.

\section{Influence of economic incentives}

We created two surveys instead of one to test the influence of economic incentives on American's WTAW. The only difference between surveys was that in one, the hypothetical use-cases included an economic incentive in their description while in the other they did not. Therefore, by comparing the results of the survey without economic incentive and the survey with an economic incentive we could analyze how economic incentives affect respondents' choice to "Accept" or "Do not accept" a specific use-case. The economic incentives were not the same in the six use-cases, they were adapted to the specific context of each use-case to make the scenario as realistic as possible. Furthermore, the quantity of the economic incentives was not specified because, given the innovativeness of the use-cases, there was no clear benchmark in the health insurance market.

\section{Statistical analysis}

We tabulated participant characteristics of the total sample $(n=1000)$ and by survey $(n=500)$. We visualized the main exposure of interest using three charts, two for the overall willingness to adopt (respondents who selected "Accept" and "Accept just if ..." ) or not do adopt (respondents who selected "Do not accept") wearables by type of use-case and by the absence or presence of economic incentive; and one for the main barriers to adopt wearables (conditions selected in "Accept just if ...").

Additionally, for the secondary outcome, we calculated the risk ratio of the WTAW in each use-case if there was an additional economic incentive and we considered a two-tailed $P<0.05$ to be statistically significant. We used poisson regression with robust variance to estimate the Relative Risk of WTAW; we adjusted for the demographic variables age group, gender, education level, income level, ethnicity, health insurance, marital status, and employment status; and clustered on state of residence to correct for correlated observations within each state. We decided to use logpoisson with robust variances over logistic regression because leading epidemiologists and biostatisticians agree that the robust Poisson models are more robust to outliers compared to the log-binomial models when estimating relative risks or risk ratios for common binary outcomes; and odds ratio yields bias when outcome is not rare (i.e. $>5 \%$ yes) $[23,24]$. Analyses used Stata software, version 13.1. (StataCorp LP, College Station, TX).

\section{Results}

Out of the total sample, 3 participants submitted an empty survey, so they were excluded from the study, reducing the sample size to 997 . In addition, 8 participants submitted the survey with at least one missing value. Given the relatively few missing values compared to the total sample size, missing data were handled through listwise deletion, meaning that we deleted all data from any participant with missing values. Regarding the general demographic characteristics of the sample, there were respondents from 46 states; $40.22 \%$ were 25 to 34 years old; $57.27 \%$ were female; $74.52 \%$ were white; $50.75 \%$ had private employer-based health insurance; $47.94 \%$ had some college or associate degree; and $20.60 \%$ had a household income of less than 25.000 per year. For virtually all variables there were no statistically significant differences between the sample of the survey with economic incentive and the one without economic incentive. The only exception was geographic state and the subcategory of education level "some college or associate degree" which was overrepresented in the sample with economic incentive $(46.89 \%$ vs $49.00 \%, P=0.044)$. Table 1 shows the demographics characteristics of the participants.

Figure 1a and b show the main results about participants' WTAW by the presence or absence of an economic incentive. Results indicated that non-willingness to adopt dropped from $33.63 \%$ non-acceptance to $28.08 \%$ non-acceptance with economic incentives. Meanwhile, approximately $53 \%$ of 
Table 1 Demographic characteristics of the sample

\begin{tabular}{|c|c|}
\hline Variable & Total sample $(n=$ \\
\hline \multicolumn{2}{|l|}{ Gender } \\
\hline Male & $42.73 \%(n=426)$ \\
\hline Female & $57.27 \%(n=571)$ \\
\hline \multicolumn{2}{|l|}{ Age group } \\
\hline 18-24 years old & $13.14 \%(n=131)$ \\
\hline 25-34 years old & $40.22 \%(n=401)$ \\
\hline 35-44 years old & $22.47 \%(n=224)$ \\
\hline 45-64 years old & $21.26 \%(n=212)$ \\
\hline 65 years or older & $2.81 \%(n=28)$ \\
\hline \multicolumn{2}{|l|}{ Ethnicity } \\
\hline White & $74.52 \%(n=743)$ \\
\hline Hispanic or Latino & $6.62 \%(n=66)$ \\
\hline Black or African American & $8.93 \%(n=89)$ \\
\hline Asian American & $7.62 \%(n=76)$ \\
\hline Other & $1.81 \%(n=18)$ \\
\hline Missing & $0.50(n=5)$ \\
\hline \multicolumn{2}{|l|}{ Highest level of education attained } \\
\hline Less than high school & $0.90 \%(n=9)$ \\
\hline High school completion & $11.13 \%(n=111)$ \\
\hline Some college or associate degree & $47.94 \%(n=478)$ \\
\hline Advanced degree & $39.62 \%(n=395)$ \\
\hline Missing & $0.40 \%(n=4)$ \\
\hline \multicolumn{2}{|l|}{ Marital status } \\
\hline Single, never married & $43.93 \%(n=438)$ \\
\hline Married or domestic partnership & $45.14 \%(n=450)$ \\
\hline Widowed & $2.61 \%(n=26)$ \\
\hline Divorced & $7.12 \%(n=71)$ \\
\hline Separated & $0.80 \%(n=8)$ \\
\hline Missing & $0.40 \%(n=4)$ \\
\hline \multicolumn{2}{|l|}{ Household income } \\
\hline Less than $25.000 \$$ per year & $20.60 \%(n=206)$ \\
\hline Between $25.000 \$$ and $34.999 \$$ per year & $13.44 \%(n=134)$ \\
\hline Between $35.000 \$$ and $49.999 \$$ per year & $17.45 \%(n=174)$ \\
\hline Between $50.000 \$$ and $74.999 \$$ per year & $23.87 \%(n=238)$ \\
\hline Between $75.000 \$$ and $99.999 \$$ per year & $13.14 \%(n=131)$ \\
\hline Between $100.000 \$$ and $149.999 \$$ per year & $9.03 \%(n=90)$ \\
\hline More than $150.000 \$$ per year & $2.21 \%(n=22)$ \\
\hline Missing & $0.20 \%(n=2)$ \\
\hline \multicolumn{2}{|l|}{ Employment status } \\
\hline Employed for wages & $62.99 \%(n=628)$ \\
\hline Self-employed & $13.74 \%(n=137)$ \\
\hline Unemployed & $10.23 \%(n=102)$ \\
\hline Student & $5.62 \%(n=56)$ \\
\hline Military & $0.50 \%(n=5)$ \\
\hline
\end{tabular}

Table 1 Demographic characteristics of the sample (Continued)

\begin{tabular}{ll}
\hline Variable & Total sample $(n=997)$ \\
\hline Retired & $3.71 \%(n=37)$ \\
Unable to work & $2.81 \%(n=28)$ \\
Missing & $0.40 \%(n=4)$ \\
Health insurance & \\
Public (Medicare or Medicaid) & $24.17 \%(n=241)$ \\
Private (employer-based) & $50.75 \%(n=506)$ \\
Private (individually purchased) & $11.74 \%(n=117)$ \\
Other & $3.01 \%(n=30)$ \\
Not insured & $9.53 \%(n=95)$ \\
Missing & $0.80 \%(n=8)$ \\
\hline
\end{tabular}

the respondents were interested to conditionally accept if under certain use-cases conditions, almost unchanged by economic incentives. However, with an economic incentive, interest to unconditionally accept increased from 13.56 to $18.78 \%$.

Regarding American's concerns about health-insurance use-cases based on wearable devices, Fig. 2 shows that out of the respondents who were interested to accept under certain conditions, $99.22 \%$ were concerned about economic benefits, data-privacy and/or technical conditions. More specifically, they placed a slightly higher importance to "free service", "free smart band" and "data not shared with third parties" than to a "service 100\% accurate" (27.16, 26.34 and $25.11 \%$ vs $20.61 \%$ respectively).

Figure 3 shows that there were important differences in WTAW between use-cases, particularly among respondents who selected "Accept if" or "Do not accept". Overall, Americans were more willing to adopt with and/or without conditions the use-cases of health promotion and early detection of diseases $(79.84 \%$ and $81.24 \%$ respectively vs an average of $69.14 \%$ ) and less willing to adopt the use-cases of adherence tracking, personalized products and services, and automated underwriting $(59.98 \%, 58.78 \%$ and $64.70 \%$ respectively vs an average of $69.14 \%$ ).

Regarding the inferential statistics, Table 2 shows the results of the influence of economic incentives on each of the use-cases based on data from wearable devices. Economic incentives involving providing healthcare credits, insurance premium discount, and/or wellness product discounts led to a significant increase in the WTAW in the use-cases of health promotion by $6 \%$ $(\mathrm{RR}=1.06$ with $\mathrm{P}=0.018)$; personalized products and services by $11 \%(\mathrm{RR}=1.11$ with $\mathrm{P}=0.018)$; and automated underwriting by $28 \%(R R=1.28$; with $P<0.001)$. Furthermore, additional economic incentives had a suggestive finding for increasing the WTAW in the use-case of adherence tracking by $7 \%(\mathrm{RR}=1.07$ with $P=0.05)$. 
A

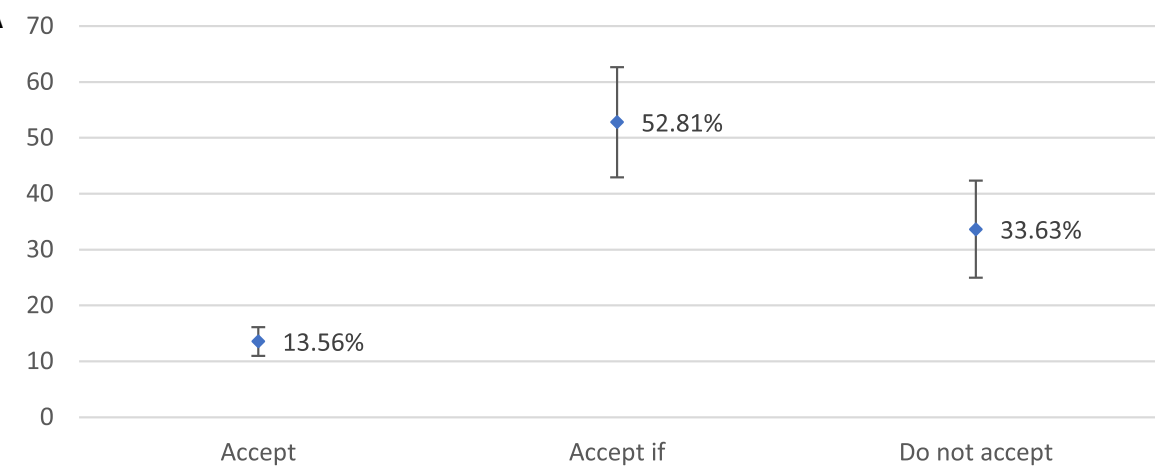

B 70

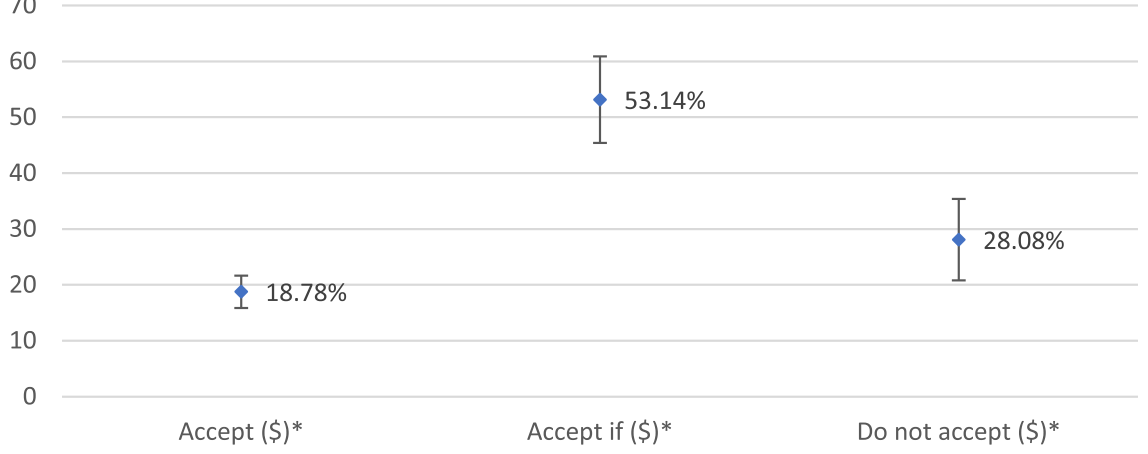

Fig. 1 a Total distribution of average percentage of acceptance without economic incentive. $\mathbf{b}$ Total distribution of average percentage of acceptance with economic incentive

\section{Discussion}

Previous studies have explained that health insurance companies could adjust their product strategies to motivate individuals to use wearable devices $[2-4,7-9,11-15]$ and even evaluated if consumers were interested to use a wearable device and share the data with their health or life insurance company in return for financial rewards for healthy behaviors $[16,17]$. Other studies have examined the adoption of wearable devices as a whole [25] or by certain groups such as the elderly [26, 27], runners [11] or health professionals [28]; and found out that individuals

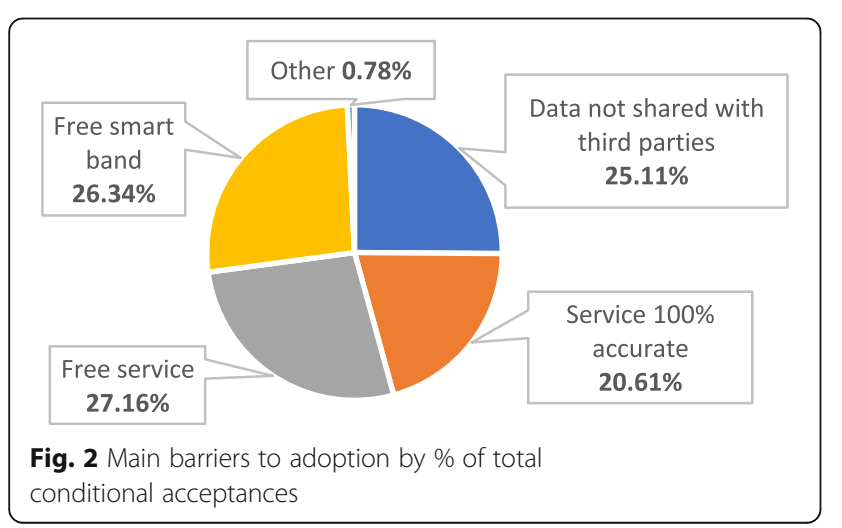

follow a risk-benefit analysis too decide to adopt healthcare wearable devices [29].

Our study builds upon those findings and provides additional insights on users' decision-making process and motivation by type of wearable-driven use-cases and contextual conditions. Even though, to the best of our knowledge, this is the first study to carefully examine individuals' WTAW in specific health-insurance use-cases; if we assume that all use-cases consist on providing a health, financial, customization and/or convenience benefits to users in exchange of them using a wearable device and sharing the data with their health insurance company, some of the results could be compared with previous data; in fact, the results of this research are similar to the ones obtained by PriceWaterhouseCoopers in $2014(69.14 \%$ vs $68 \%$ of respondents interested to adopt respectively) [17]. The study published by Life Happens and LIMRA in 2016 shows higher adoption rates $(16.17 \%$ of respondents interested to adopt regardless of the conditions vs $30 \%$ of respondents very or extremely likely to adopt) but it is focused on life insurance, not health insurance [16]. Opposed to the study of Alley et all [25], our findings show that not only accuracy but also the financial cost of the wearable device is among the top barriers of the respondents, and that fewer citizens are not interested in using a wearable 


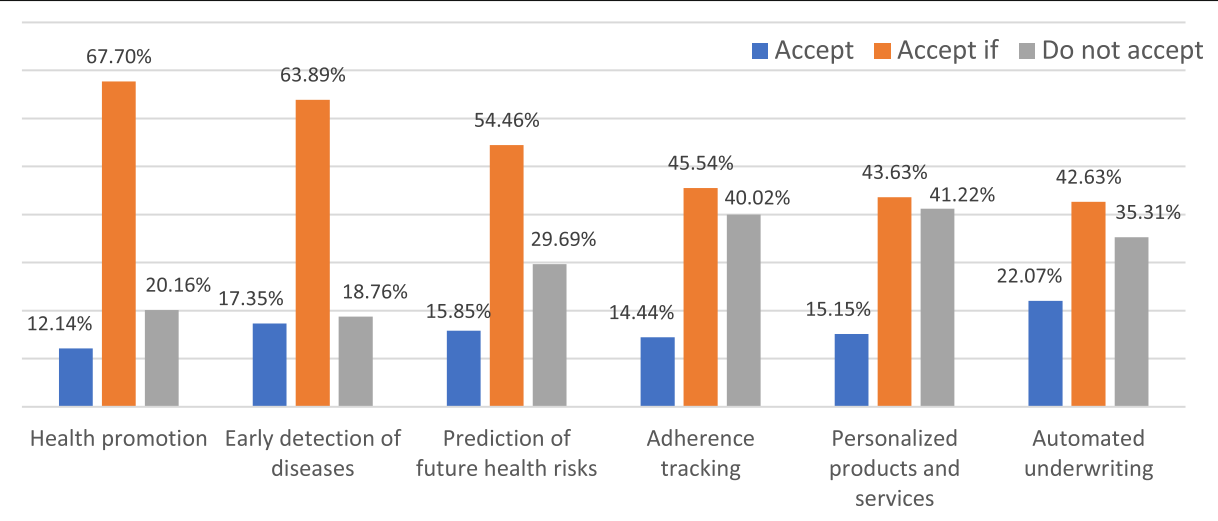

Fig. 3 Willingness to adopt wearables in each use-case in \%

device (30.85\% vs $44 \%$ respectively), but their research focused on the willingness to use a fitness tracker in general rather than specific wearable-driven use-case involving data-sharing with health insurance companies.

The main implications of our study are that, on the one hand, it ratifies that most Americans are willing to adopt wearable devices with behavioral and economic incentives by health insurance wellness programs, and on the other hand, it shows that not all use-cases are valued equally and that there are important barriers regarding economic, accuracy and data-privacy conditions. Another important finding is that Americans are more willing to adopt wearables if the use-cases focus on health benefits and/or there are additional economic incentives.

These insights are particularly relevant because the U.S. has signed into law the Republican Party's repeal of a key provision of the Affordable Care Act (ACA), the individual mandate [30]. Among other changes, from 2019 onwards, people who have no health insurance and who are not exempt from the mandate under current law will not be penalized for not holding an active health insurance policy. Consequently, there is an expected exodus of young and healthy individuals from the health care marketplace, leaving sicker patients in the market for insurance. It is estimated that both the number of uninsured people could increase by 4 million in 2019, and average premiums in the ACA marketplaces could rise by approximately $10 \%$ [31].

This reform has a major impact because it creates adverse selection. As pointed out by the American Academy of Actuaries in a letter to Congress in March 2017, the sharpest decrease in insured rates would come from healthy individuals without immediate health care needs, and thus, the quality of the risk pool and health insurer's ability to cover claims would diminish [32]. Therefore, health insurers will have even greater incentives to "cherry picking", to attract young and healthy policy holders. That is especially relevant because wearables have been mostly purchased by individuals who have a healthy lifestyle [33] and the adoption of wearable devices tends to decline with age [34]. As a result, use-cases based on data from wearable devices could be potentially a very key incentive approach for health insurers to appeal to the younger and healthier segments of the population, and thereby retaining them to stabilize the insurance premiums in the risk pool. The results of this research can help to predict how Americans could react if health insurers offer wellness programs based on wearable devices,

Table 2 Economic incentives on WTAW in each of the health insurance use-cases based on wearable device purpose of usage scenarios

\begin{tabular}{|c|c|c|c|c|}
\hline $\begin{array}{l}\text { Health insurance use-case based on wearable } \\
\text { devices purpose of usage }\end{array}$ & $\begin{array}{l}\text { RELATIVE RISK of WTAW with } \\
\text { an additional economic incentive }\end{array}$ & $P$ value & \multicolumn{2}{|c|}{ [95\% Conf. Interval] } \\
\hline Health promotion scenario & 1.06 & 0.018 & 1.01 & 1.11 \\
\hline Early detection of diseases scenario & 1.03 & 0.21 & 0.98 & 1.08 \\
\hline Prediction of future health risks scenario & 0.78 & 0.27 & 0.51 & 1.21 \\
\hline Adherence tracking scenario & 1.07 & 0.05 & 1.00 & 1.15 \\
\hline Personalized products scenario & 1.11 & 0.018 & 1.01 & 1.21 \\
\hline Automated underwriting scenario & 1.28 & $<0.001$ & 1.20 & 1.37 \\
\hline
\end{tabular}

Note. All models were adjusted for the demographic variables age group, gender, education level, income level, ethnicity, health insurance, marital status, and employment status; and clustered on state of residence to correct for correlated observations within each state

$P$ values of $<0.05$, considered to be statistically significant, are presented in bold 
and thus, to better understand how the value of a usecase and its' conditions could be modified to maximize the chances to attract or retain health insurance policy holders.

Given the exploratory nature of this research the results should be interpreted accordingly. This research cannot claim to be representative of the whole U.S. because there could be a sampling bias due to the relatively limited size of the sample and that there were no respondents from four states. Another limitation is that the order of the use-cases based on wearable devices was not randomized, and thus, there could be a questionorder bias. In addition, the quantity of the economic incentives was not specified so it is not possible to conclude how substantial the economic incentives should be to increase American's WTAW. Therefore, future research could address if the amount and type of economic incentive has a significant influence on the WTAW by health insurance wellness programs.

\section{Conclusion}

Under the adequate economic, data privacy and technical conditions, two out of three Americans would be willing to accept health insurance wellness programs based on wearable devices, particularly if they have benefits related to health promotion and primary prevention. Therefore, health insurance wellness programs based on wearable devices could be potentially a very key incentive approach for health insurers to appeal to the younger and healthier segments of the population, and thereby retaining them to stabilize the insurance premiums in the risk pool.

\section{Supplementary information}

Supplementary information accompanies this paper at https://doi.org/10. 1186/s12889-019-7920-9.

Additional file 1. Surveys.

\section{Abbreviations}

ACA: Affordable care act; WTAW: Willingness to adopt wearables

\section{Acknowledgements}

Not applicable.

\section{Authors' contributions}

All four authors have read and approved the manuscript. The individual contributions of each author are described below: DSF and ELD contributed to the design and implementation of the research, to the analysis of the results and to the writing of the manuscript. AD. Ding contributed to the discussion of the results and writing of the final manuscript. EBK. Bayro-Kaiser contributed to the planning of the idea, provided critical feedback and helped shape the research.

\section{Funding}

Not applicable.

\section{Availability of data and materials}

The datasets used and/or analyzed during the current study are available from the corresponding author on reasonable request.

\section{Ethics approval and consent to participate}

The institutional review board of Management Center Innsbruck deemed this research exempt of ethics assessment. All participants voluntarily confirmed their willingness to participate in the study by explicitly accepting a written informed consent prior to the survey.

\section{Consent for publication}

Not applicable.

\section{Competing interests}

The authors declare that they have no competing interests.

\section{Author details}

${ }^{1}$ Management Center Innsbruck, Innsbruck, Austria. ${ }^{2}$ California Advanced Imaging, Novato, CA, USA. ${ }^{3}$ Institute for Artificial Intelligence, University of Bremen, Bremen, Germany. ${ }^{4}$ Department of Nutrition, Harvard Chan School of Public Health, Boston, MA 02115, USA. ${ }^{5}$ Microclinic International, San Francisco, CA, USA. ${ }^{6}$ Health Finance Institute, Arlington, VA, USA. ${ }^{7}$ Federal Health Division, General Dynamics Information Technology, Falls Church, VA, USA.

Received: 8 July 2019 Accepted: 8 November 2019

Published online: 16 December 2019

\section{References}

1. Cisco Systems. Cisco visual networking index: global Mobile 2016 [Internet]. 2016. Available from: http://www.statista.com/statistics/487291/global-.

2. Kostkova P, Brewer H, de Lusignan S, Fottrell E, Goldacre B, Hart G, et al. Who Owns the Data? Open Data for Healthcare. Front public Heal [Internet]. 2016 [cited 2017 Jan 7];4:7. Available from: http://www.ncbi.nlm.nih.gov/ pubmed/26925395.

3. Soreon Research. The wearable health revolution: how smart Wearables disrupt the Healthcare sector. 2014

4. Dimitrov D V. Medical Internet of Things and Big Data in Healthcare. Healthc Inform Res [Internet]. 2016 22(3):156-163. [cited 2017 Jan 7]; Available from: http://www.ncbi.nlm.nih.gov/pubmed/27525156.

5. Herzlinger RE. Why Innovation in Health Care Is So Hard. Harv Bus Rev [Internet]. 2006; Available from: https://hbr.org/2006/05/why-innovation-inhealth-care-is-so-hard

6. Barnett JC, Vornovitsky MS, Davis KE, Dowdy R, Evers S, Fung RC, et al. Health insurance coverage in the United States: 2015. 2016;

7. PriceWaterhouseCoopers. Insurance 2020: PriceWaterhouseCoopers Insur 2020 [Internet]. 2012;(January):24. Available from: http://www.pwc.com/ gx/en/industries/financial-services/insurance/publications/future-ofinsurance.html

8. PriceWaterhouseCoopers. Insurance 2020 \& beyond: Necessity is the mother of reinvention [Internet]. 2015. Available from: https://www.pwc.com/gx/en/ insurance/publications/assets/pwc-insurance-2020-and-beyond.pdf

9. Munich RE. Data is wearable? An early look at wearables for life and living benefits insurance; 2015.

10. Brown EA. The Fitbit Fault Line: Two Proposals to Protect Health and Fitness Data at Work. Yale J Health Policy Law Ethics [Internet]. 2016 [cited 2017 Jan 23];16(1). Available from: http://digitalcommons.law.yale.edu/yjhple

11. Wiesner M, Zowalla R, Suleder J, Westers M, Pobiruchin M. Technology Adoption, Motivational Aspects, and Privacy Concerns of Wearables in the German Running Community: Field Study. JMIR mHealth uHealth [Internet]. 2018 Dec 14 [cited 2019 Jan 10];6(12):e201. Available from: http://mhealth. jmir.org/2018/12/e201/

12. Tedesco S, Barton J, O'Flynn B. A Review of Activity Trackers for Senior Citizens: Research Perspectives, Commercial Landscape and the Role of the Insurance Industry. Sensors (Basel) [Internet]. 2017 Jun 3 [cited 2018 Oct 28]; 17(6). Available from: http://www.ncbi.nlm.nih.gov/pubmed/28587188.

13. Kostkova P. Grand Challenges in Digital Health. Front Public Heal [Internet]. 2015 May 5 [cited 2017 Jan 7];3:134. Available from: http://www.frontiersin. org/Digital_Health/10.3389/fpubh.2015.00134/full

14. Li X, Dunn J, Salins D, Zhou G, Zhou W, Schüssler-Fiorenza Rose SM, et al. Digital Health: Tracking Physiomes and Activity Using Wearable Biosensors 
Reveals Useful Health-Related Information. Kirkwood T, editor. PLOS Biol [Internet]. 2017 Jan 12 [cited 2017 Jan 15];15(1):e2001402. Available from: http://dx.plos.org/10.1371/journal.pbio.2001402

15. Li H, Wu J, Gao Y, Shi Y. Examining individuals' adoption of healthcare wearable devices: An empirical study from privacy calculus perspective. Int J Med Inform [Internet]. 2016 [cited 2019 Jan 20];88:8-17. Available from: http://www.ncbi.nlm.nih.gov/pubmed/26878757.

16. Life Happens [Internet]. 2016 [cited 2019 Jan 20]. Available from: https:// lifehappens.org/industry-resources/agent/barometer2016/

17. PriceWaterhouseCoopers. The Wearable Future [Internet]. 2014 [cited 2019 Jan 20]. Available from: https://www.pwc.com/mx/es/industrias/archivo/2 014-11-pwc-the-wearable-future.pdf

18. Buhrmester M, Kwang T, Gosling SD. Amazon's Mechanical Turk. Perspect Psychol Sci [Internet]. 2011 Jan 3 [cited 2018 Mar 24];6(1):3-5. Available from: http://journals.sagepub.com/doi/10.1177/1745691610393980

19. Paolacci G, Chandler J, Wilson W, Ipeirotis PG, Stern LN. Running experiments on Amazon Mechanical Turk. Judgm Decis Mak. 2010;5(5).

20. Goodman JK, Cryder CE, Cheema A. Data Collection in a Flat World: The Strengths and Weaknesses of Mechanical Turk Samples. J Behav Decis Mak [Internet]. 2013 Jul 1 [cited 2018 Mar 24];26(3):213-24. Available from: http:// doi.wiley.com/10.1002/bdm.1753

21. Gurdus E. UnitedHealthcare and Fitbit to pay users up to $\$ 1,500$ to use devices [Internet]. 2017 [cited 2017 Jan 24]. Available from: http://www. cnbc.com/2017/01/05/unitedhealthcare-and-fitbit-to-pay-users-up-to-1500to-use-devices.html

22. Oscar. https://www.hioscar.com/plans [Internet]. 2017. Available from: https://www.hioscar.com/plans

23. Chen W, Shi J, Qian L, Azen SP. Comparison of robustness to outliers between robust poisson models and log-binomial models when estimating relative risks for common binary outcomes: a simulation study. BMC Med Res Methodol [lnternet]. 2014 Jun 26 [cited 2019 Aug 23];14:82. Available from: http://www.ncbi.nlm.nih.gov/pubmed/24965498.

24. Spiegelman D, Hertzmark E. Easy SAS Calculations for Risk or Prevalence Ratios and Differences. Am J Epidemiol [Internet]. 2005 Jun 29 [cited 2019 Aug 23];162(3):199-200. Available from: https://academic.oup.com/aje/ article-lookup/doi/10.1093/aje/kwi188

25. Alley S, Schoeppe S, Guertler D, Jennings C, Duncan MJ, Vandelanotte C. Interest and preferences for using advanced physical activity tracking devices: results of a national cross-sectional survey. BMJ Open [Internet]. 2016 [cited 2019 Jan 10];6(7):e011243. Available from: http://www.ncbi.nlm. nih.gov/pubmed/27388359.

26. Mercer K, Giangregorio L, Schneider E, Chilana P, Li M, Grindrod K. Acceptance of Commercially Available Wearable Activity Trackers Among Adults Aged Over 50 and With Chronic IIIness: A MixedMethods Evaluation. JMIR mHealth uHealth [Internet]. 2016 Jan 27 [cited 2019 Jan 10];4(1):e7. Available from: http://www.ncbi.nlm.nih.gov/ pubmed/26818775.

27. Puri A, Kim B, Nguyen O, Stolee P, Tung J, Lee J. User Acceptance of WristWorn Activity Trackers Among Community-Dwelling Older Adults: Mixed Method Study. JMIR mHealth uHealth [Internet]. 2017 Nov 15 [cited 2019 Jan 20];5(11):e173. Available from: http://www.ncbi.nlm.nih.gov/pubmed/2 9141837.

28. Allouch S Ben, van Velsen L. Fit by Bits: An Explorative Study of Sports Physiotherapists' Perception of Quantified Self Technologies. Stud Health Technol Inform [Internet]. 2018 [cited 2019 Jan 20];247:296-300. Available from: http://www.ncbi.nlm.nih.gov/pubmed/29677970.

29. Li H, Wu J, Gao Y, Shi Y. Examining individuals' adoption of healthcare wearable devices: an empirical study from privacy calculus perspective. Int J Med Inform. 2016;88:8-17.

30. Tracer Z, Natasha R. GOP Tax Compromise Would Repeal Obamacare's Individual Mandate [Internet]. Bloomberg. 2017 [cited 2018 Jan 8]. Available from: https://www.bloomberg.com/news/articles/2017-12-13/obamacarecoverage-requirement-undone-in-gop-tax-compromise

31. Congressional Budget Office. Repealing the Individual Health Insurance Mandate: An Updated Estimate [Internet]. 2017 [cited 2018 Jan 8]. Available from: https://www.cbo.gov/system/files/115th-congress-2017-2018/ reports/53300-individualmandate.pdf

32. American Academy of Actuaries. Re: H.R. 1628, American Health Care Act (AHCA) [Internet]. 2017 [cited 2018 Jan 9]. Available from: http://www. actuary.org/files/publications/AHCA_comment_letter_032217.pdf
33. Piwek $L$, Ellis DA, Andrews S, Joinson A, Maisel W, Ho J. The Rise of Consumer Health Wearables: Promises and Barriers. PLOS Med [Internet]. 2016 Feb 2 [cited 2017 Jul 11];13(2):e1001953. Available from: http://dx.plos. org/10.1371/journal.pmed.1001953

34. PriceWaterhouseCoopers. The Wearable Life 2.0: Connected living in a wearable world. Consum Intell Ser [Internet]. 2014;55. Available from: https://www.pwc.com/us/en/industry/entertainment-media/assets/pwc-ciswearables.pdf

\section{Publisher's Note}

Springer Nature remains neutral with regard to jurisdictional claims in published maps and institutional affiliations.
Ready to submit your research? Choose BMC and benefit from:

- fast, convenient online submission

- thorough peer review by experienced researchers in your field

- rapid publication on acceptance

- support for research data, including large and complex data types

- gold Open Access which fosters wider collaboration and increased citations

- maximum visibility for your research: over $100 \mathrm{M}$ website views per year

At BMC, research is always in progress.

Learn more biomedcentral.com/submissions 